\title{
MICROCLIMA E CONFORTO TÉRMICO DE REMANESCENTES FLORESTAIS URBANOS NO MUNICÍPIO DE JATAÍ - GO
}

\author{
MICROCLIMATE AND THERMAL COMFORT OF URBAN FOREST FRAGMENTS IN \\ THE MUNICIPALITY OF JATAÍ- GO
}

Brenda Moraes Melo ${ }^{1}$, Daniela Pereira Dias²

\section{RESUMO}

O objetivo deste estudo foi determinar o microclima e o conforto térmico proporcionados por três áreas de remanescentes florestais urbanos no município de Jataí - GO, bem como verificar o efeito do resfriamento, umidificação e sombreamento proporcionado por essas áreas. As áreas estudadas foram: Mata da Roda d'água (12 ha), Parque Ecológico IPSG (2 ha) e Mata do Açude (30 ha). Dados de temperatura, umidade relativa do ar e luminosidade foram coletados e utilizados para determinação do efeito do resfriamento, umidificação e sombreamento das florestas sobre o meio urbano. As florestas também foram classificadas de acordo com o conforto térmico oferecido, com base no índice UTCI. A Mata do Açude proporciona microclima mais confortável termicamente do que as demais. Em contrapartida, a Mata da Roda d'água apresentou o menor conforto térmico entre os remanescentes florestais, devido à maior quantidade de clareiras, proporcionando maior radiação solar e umidade relativa do ar em seu interior. A Mata do Açude apresentou ausência de estresse térmico, enquanto que a Mata da Roda d'água e a borda do Parque Ecológico do IPSG apresentaram moderado estresse por calor. O grau de conservação das florestas, bem como a proximidade com área urbanizada de Jataí influenciam seu microclima e conforto térmico.

Palavras-chave: Áreas verdes; Clima urbano; Planejamento urbano.

\section{ABSTRACT}

The objective of this study was to determine the microclimate and thermal comfort of three urban forest fragments in the municipality of Jataí - GO, and to verify the cooling, humidifying and shading effect provided by forests. The urban forest areas studied were: Roda d'água Forest (12 ha), Ecological Park IPSG (2 ha) and Açude Forest (30 ha). Air temperature, relative humidity and luminosity data were collected and used to determine the cooling, humidifying and shading effect of forests on the urban environment. The forests were also classified according to the thermal comfort offered, based on the UTCI index. Açude Forest provides microclimate more thermally comfortable than the other urban forests analyzed. On the other hand, Roda d'água Forest presented the least thermal comfort among the urban forests, due to the greater number of clearings, providing greater solar radiation and air relative humidity. Açude Forest presented no thermal stress and Roda d'água Forest and Ecological Park IPSG's edge presented moderate heat stress. The conservation degree, as well as the proximity to urbanized area in Jataí influence their microclimate and thermal comfort.

Keywords: Green areas; Urban climate; Urban planning.

Recebido em 02.05.2019 e aceito em 27.06.2019

1 Engenheira Florestal. Discente do curso de Engenharia Florestal. Universidade Federal de Goiás - Regional Jataí. Jataí/GO. Email: moraesemelo@gmail.com

2 Engenheira Florestal. Doutor em Ciências de Florestas Tropicais. Prof.a na Universidade Federal de Goiás - Regional Jataí. Jataí/GO. Email: danieladias@ufg.br 


\section{INTRODUÇÃO}

As florestas, além de fornecerem condições de qualidade de vida e bem-estar humano, por meio do fornecimento de serviços ecossistêmicos de suporte (produção primária, ciclagem, formação do solo), provisão (alimentos, água, madeira, combustível), regulação (clima, enchentes) e culturais, para aqueles que residem no perímetro urbano ou periurbano, são também componentes importantes para a paisagem urbana, por razões ecológicas e sociopsicológicas (FERREIRA et al., 2016). Todos os conjuntos de árvores situados dentro do perímetro urbano são definidos como floresta urbana, podendo ser de domínio público ou particular e dividindo-se em áreas verdes e arborização de ruas (BIONDI, 2015). Várias são as tipologias de florestas urbanas (MARTINI et al., 2018), e estas suprem as necessidades dos habitantes, para usufruto dos espaços de lazer e descanso, e da realização de metas estabelecidas pelas políticas públicas devido as suas vantagens (RODRIGUES et al., 2017).

As florestas urbanas tornam-se cada vez mais necessárias e, atualmente, passam a ser vistas como elemento de promoção de qualidade de vida a comunidade ao redor (RODRIGUES et al., 2017). Mesmo onde as florestas urbanas são encontradas em pequenos fragmentos, estas exercem um papel importante na amenização climática (NASCIMENTO; OLIVEIRA, 2011). Isto porque possibilitam a existência de microclimas urbanos diferenciados por meio do sombreamento, da redução da velocidade dos ventos, da proteção solar ao ambiente urbano edificado, da redução das temperaturas, da evapotranspiração e da retenção de umidade do solo e do ar. O microclima pode variar com o tipo de floresta urbana (MARTINI; BIONDI, 2015) e de acordo com o local, se mais interno ou externo (MARTINI et al., 2017). Isso ocorre devido à densidade da copa das árvores, tamanho da copa, altura das árvores e radiação solar (ZHANG et al., 2013). Pois, árvores com maior altura e maior área de projeção da copa promovem maior efeito de sombreamento, que por sua vez, aumenta o efeito de resfriamento e umidificação no interior das florestas (WANG et al., 2017).

A dinâmica entre o ambiente natural e antrópico nas cidades, que possuem sistemas diferentes que interagem entre si, constituindo um ambiente intermediário com características particulares devem ser analisadas de forma integral, para um melhor entendimento das interações que ali ocorrem e da relação entre dinâmica florestal e conforto térmico (FERREIRA et al., 2016). A quantificação e a qualificação de como a vegetação contribui para o conforto térmico em espaços urbanos tem sido investigada em várias cidades (LABAKI et al., 2011; MARTINI; BIONDI, 2015; DACANAL et al. 2010, SILVA et al. 2015; JUSTI et al., 2019), pois esta proporciona a atenuação da radiação solar, o que afeta a temperatura e a umidade de áreas próximas. O conforto térmico proporcionado pela presença da vegetação podem variar de acordo com a sua morfologia (JUSTI et al., 2019), o tipo de floresta urbana (MARTINI; BIONDI, 2015), 
com sua concentração/distribuição na malha urbana (SILVA et al., 2015), bem como quando considera-se o interior e o exterior (RODRIGUES et al., 2017; MARTINI et al., 2017). Dessa forma, a conservação e a manutenção de florestas urbanas garantem melhores condições de conforto térmico nas cidades, o que impacta diretamente na qualidade de vida da população residente.

Neste contexto, estudar o efeito das florestas sobre o meio urbano tem fundamental importância para valorizar o papel das florestas urbanas. Por esse motivo, a presente pesquisa parte da hipótese de que florestas com maior área proporcionam maior conforto térmico e florestas que passaram por maiores intervenções antrópicas apresentam menores efeitos de sombreamento, resfriamento e umidificação sobre o ambiente. Além disso, devido ao maior efeito de borda, florestas menores tendem a apresentar variação microclimática inferior quando comparadas às florestas maiores. O objetivo deste estudo foi comparar o microclima e o conforto térmico proporcionado por três remanescentes florestais urbanos do município de Jataí - GO, bem como verificar o efeito do sombreamento, resfriamento e umidificação proporcionado pelas florestas.

\section{MATERIAL E MÉTODOS}

As áreas de remanescentes florestais selecionadas para este estudo localizam-se na área urbana no município de Jataí, Goiás, que se encontra predominantemente sob o domínio do bioma Cerrado. Podem ser encontradas em Jataí diferentes fitofisionomias de Cerrado, tais como: Cerradão, Cerrado sentido restrito, Campo sujo, Campo limpo e Mata de galeria, mas estes atualmente encontram-se bastantes fragmentados. Também foi encontrado um fragmento urbano de Mata Atlântica no município de Jataí, com vegetação do tipo Floresta Estacional Semidecidual (JÚNIOR et al., 2016), área conhecida como Mata do Açude. Com pluviosidade anual média de $1645 \mathrm{~mm}$, Jataí tem temperatura média anual de 23,7 ํㅡ e altitude média de 676 m (INMET, 2018). De acordo com a classificação climática de Köppen-Geiger, o município possui clima do tipo Aw, tropical com estação seca no inverno. O latossolo roxo é predominante na área urbana de Jataí, uma classe de solo considerado poroso, permeável, com textura muito argilosa e profundidade superior a $2 \mathrm{~m}$ (SCOPEL et al., 2002).

Os remanescentes florestais estudados foram denominados como Mata da roda d'água

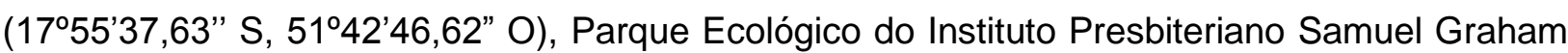
(IPSG) $\left(17^{\circ} 52^{\prime} 52.00^{\prime \prime S}, 5^{\circ} 43^{\prime} 40.29 " O\right)$ e Parque Municipal Natural da Mata do Açude $\left(17^{\circ} 51^{\prime} 33.56 " \mathrm{~S}, 5^{\circ} 43^{\prime} 41.13^{\prime \prime} \mathrm{O}\right)$ e selecionados para este estudo por possuírem diferentes 
localizações e características vegetacionais, além de apresentarem formatos e áreas diferentes (Figura 1).
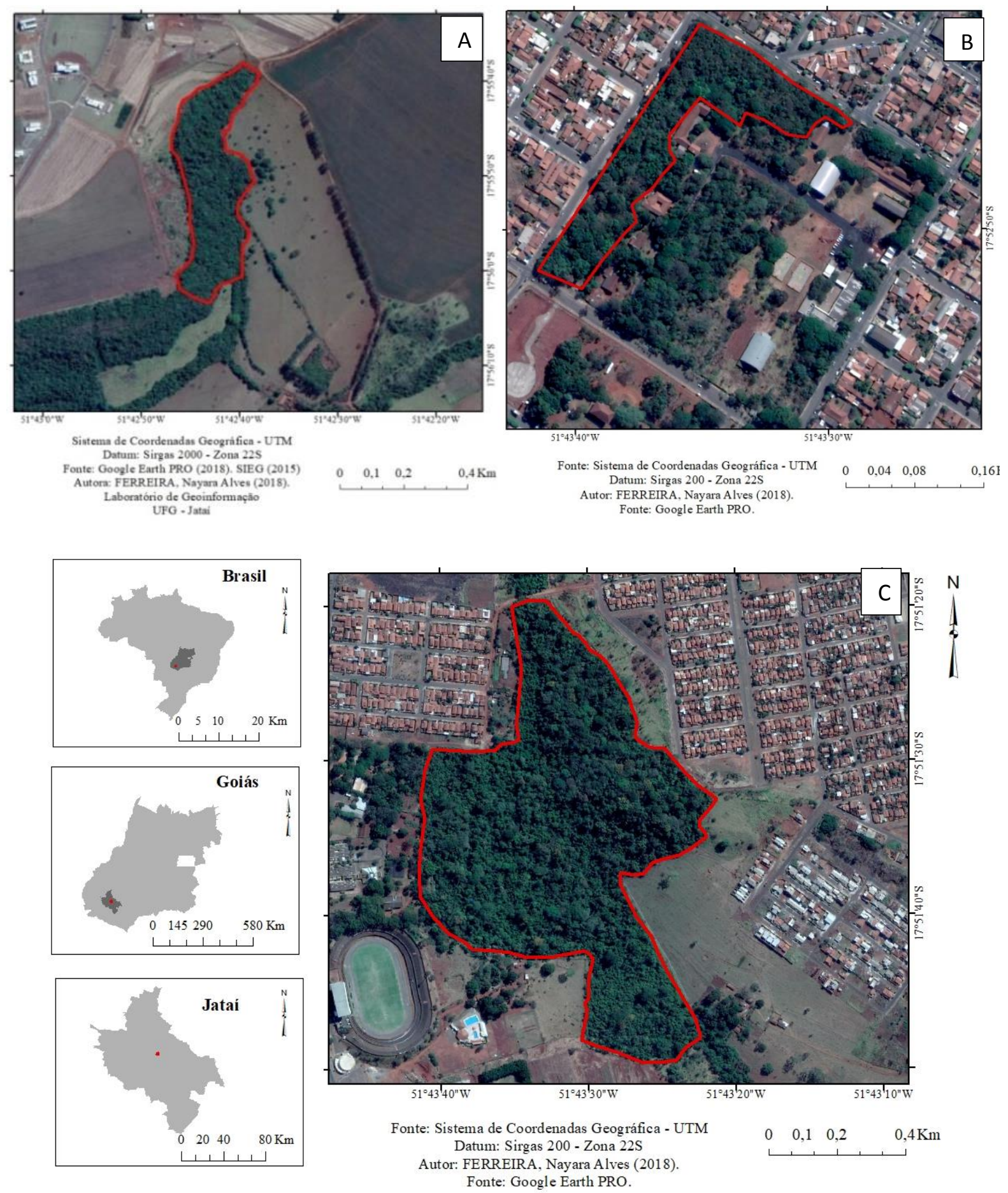

Fonte: Ferreira, N A. (2018)

Figura 1. Localização dos remanescentes florestais urbanos estudados no município de Jataí - GO: Mata da roda d'água (A), Parque Ecológico IPSG (B) e Mata do Açude (C)

Figure 1. Urban forest fragments location in the municipality of Jataí - GO: Roda d'água Forest $(A)$, Ecological Park IPSG (B) and Açude Forest (C) 
A Mata da Roda d’água, localizada na Cidade Universitária da Universidade Federal de Goiás/Regional Jataí (UFG/REJ), possui área de 12 ha com remanescente de mata de galeria (fitofisionomia do bioma Cerrado), nas margens do córrego Correias. Este remanescente tem em seu entorno monocultivos agrícolas (Figura 1A). Em estudo realizado com a regeneração natural da Mata da Roda d'água, verificou-se que $87 \%$ das espécies que ocorrem na área possuem dispersão zoocórica, $73 \%$ são consideradas não pioneiras e as famílias Myrtaceae, Sapindaceae, Monimiaceae e Rubiaceae estavam em maior número (OLIVEIRA et al., 2015). Esta área possui elevado grau de perturbação, caracterizada principalmente pela presença de várias clareiras e cipós.

O Parque Ecológico do IPSG possui 2 ha de cerradão, fitofisionomia florestal do cerrado, estando localizado no centro da cidade de Jataí. Este Parque possui trilha interna para passeio, é circundado por residências e comércios no centro do município (Figura 1B) e pertencente à Escola Instituto Samuel Graham.

A Mata do Açude (30 ha), uma unidade de conservação municipal do tipo proteção integral, tem vegetação característica do bioma Mata Atlântica do tipo Floresta Estacional Semidecidual, cortada pelo córrego do Açude. As famílias botânicas com maior número de indivíduos nesta área são: Meliaceae, Piperaceae, Sapindaceae, Fabaceae e Lauraceae (JÚNIOR et al., 2016). Ainda segundo o mesmo autor, 76\% das espécies encontradas possuem síndromes de dispersão zoocórica e $40 \%$ das espécies pertence ao grupo ecológico das pioneiras. A Mata do Açude está localizada no extremo oeste do município de Jataí (Figura 1C), tendo na vizinhança residências, comércios e uma pequena propriedade rural que exerce atividade pecuária.

Os dados micrometeorológicos de umidade relativa do ar, temperatura e luminosidade foram coletados com um termo-higro-anemômetro-luxímetro digital (LM 8000) durante os meses de abril e maio de 2018. Tais meses foram definidos de acordo com a média histórica de Jataí, disponibilizada pelo Instituto Nacional de Meteorologia (INMET), considerando a redução da precipitação que ocorre neste período, condição ideal para coleta dos dados. A temperatura do ar, a umidade relativa do ar e a luminosidade foram obtidas entre 13:00 e 16:00 h nas áreas estudadas simultaneamente. O horário de coleta de dados foi estabelecido devido a corresponderem ao período de elevados valores de temperatura do ar e radiação solar, bem como para evitar possíveis interferências humanas na coleta de dados e no adequado funcionamento dos equipamentos. Na Mata do Açude e na Mata da Roda d'água foram coletadas dados microclimáticos na borda (10 $\mathrm{m}$ a partir da margem do remanescente), meio (região central do fragmento florestal) e interior (margem do rio). Já no Parque do IPSG, os dados também foram coletados na borda e meio da floresta, porém o interior foi considerado a trilha de passeio utilizada pelos visitantes. Foram selecionados 10 pontos em cada local descrito acima, 
totalizando 30 pontos de coleta em cada floresta, pontos estes distantes no mínimo 10 metros entre si. A escolha dos pontos se deu de forma aleatória para que se tivesse uma maior representatividade das variações microclimáticas internas dos três remanescentes florestais. Em cada um dos locais de coleta de dados, estes foram coletados em intervalos de 15 minutos, totalizando 1440 leituras em cada remanescente estudado.

Além da obtenção das variáveis micrometeorológicas e suas respectivas médias para cada floresta estudada, foram calculados, de acordo com a metodologia adotada por Zhang et al. (2013), o efeito de sombreamento, efeito de resfriamento e o efeito de umidificação, tratandose da diferença entre as variáveis no interior da floresta e área externa (estação meteorológica). O efeito de resfriamento, bem como o efeito de sombreamento, foi calculado a partir da diferença entre os valores de temperatura e luminosidade, respectivamente, coletados na estação meteorológica e os obtidos nos diferentes locais dos remanescentes florestais urbanos (borda, meio e interior). Por outro lado, o efeito de umidificação foi determinado a partir dos valores de umidade relativa do ar medida nos remanescentes diminuídos dos encontrados em área externas aos mesmos. Os dados microclimáticos externos às florestas foram obtidos pela estação meteorológica automática de Jataí situada na Universidade Federal de Goiás - Regional Jataí. Os equipamentos utilizados para coleta de variáveis microclimáticas nos remanescentes florestais urbanos foram inicialmente calibrados e aferidos com a estação automática.

O conforto térmico proporcionado pelos remanescentes florestais urbanos foi calculado por meio do Índice Universal de Clima Termal (UTCI), de acordo com metodologia proposta por Martini et al. (2017). O UTCI foi calculado no software Bioklima 2.6 (IGP, 2019). As classes de UTCI e níveis de estresse térmico foram calculadas e atribuídas para cada remanescente florestal estudado, assim como para os diferentes locais em cada remanescente. Foi considerado como oferecendo moderado estresse térmico para calor, quando valores entre 26 e $32^{\circ} \mathrm{C}$ foram encontrados (BLAŻEJCZYK et al., 2010). Considerou-se que locais que apresentaram valores abaixo de $26^{\circ} \mathrm{C}$ possuíam conforto térmico (sem estresse).

Os dados microclimáticos e de conforto térmico, assim como os efeitos de resfriamento, umidificação e sombreamento, foram submetidos à ANOVA e teste Tukey a $5 \%$ de probabilidade para separação das médias obtidas.

\section{RESULTADOS E DISCUSSÃO}

Os remanescentes florestais urbanos apresentaram valores médios de temperatura do ar, umidade relativa do ar e luminosidade em seu interior significativamente diferentes entre si (Figura 2). A Mata do Açude foi o remanescente florestal que apresentou menor temperatura do 
ar e luminosidade e maior umidade relativa do ar, quando comparada aos outros remanescentes (Figura 2). Apesar da umidade relativa do ar da Mata do Açude ter sido estatisticamente igual à da Mata da Roda d’água, esta última apresentou maior luminosidade e temperatura do ar. O Parque do IPSG se igualou às condições de luminosidade interna da Mata da roda d'água, mas obteve menores valores de umidade relativa do ar (Figura 2).
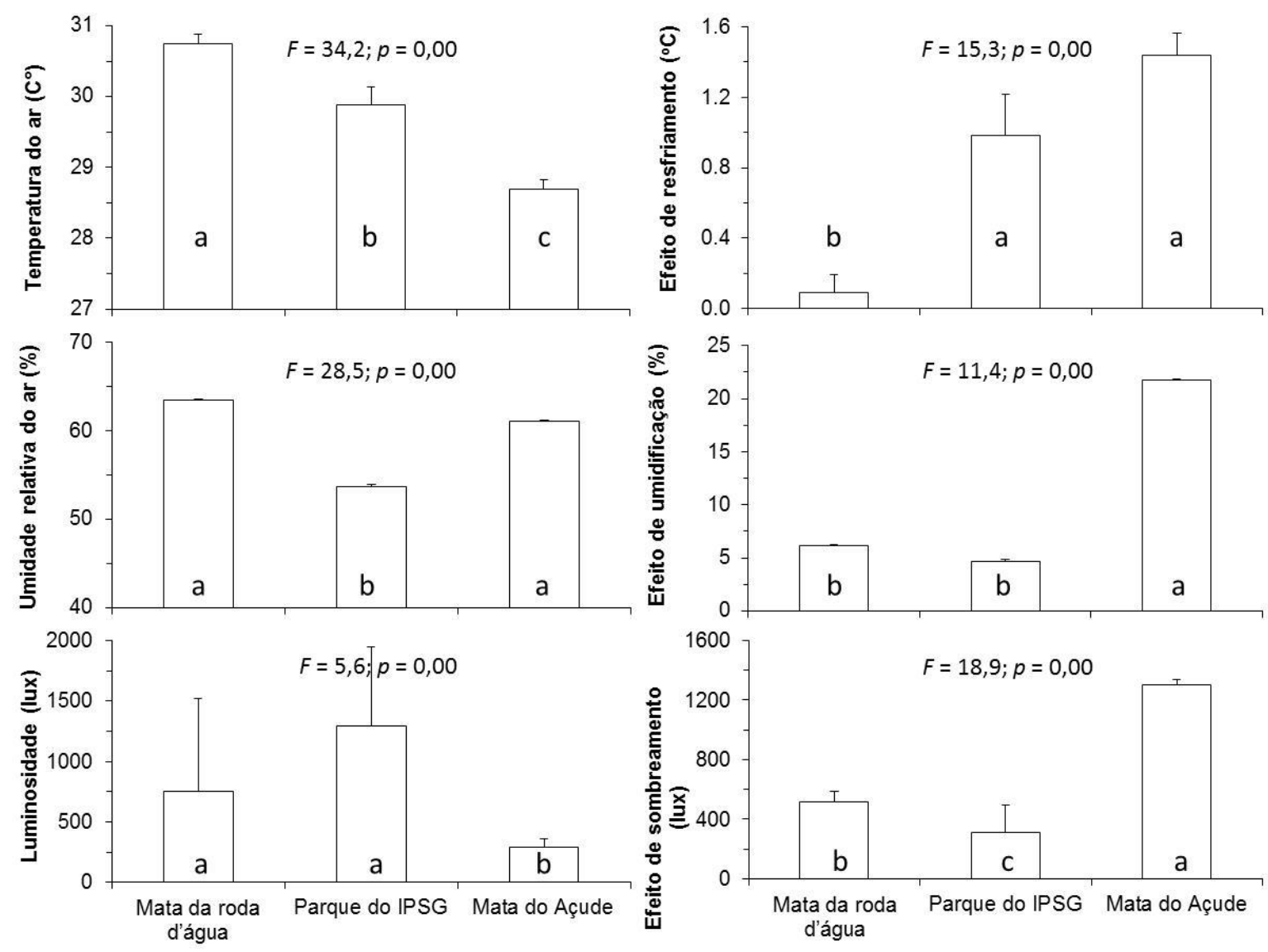

Figura 2. Temperatura do $\operatorname{ar}\left({ }^{\circ} \mathrm{C}\right)$, umidade relativa do ar (\%), luminosidade (lux) e efeito de resfriamento $\left({ }^{\circ} \mathrm{C}\right)$, umidificação (\%) e sombreamento (lux) de remanescentes florestais urbanos em Jataí - GO (Mata da roda d'água, Parque Ecológico IPSG e Mata do Açude)

Figure 2. Air temperature $\left({ }^{\circ} \mathrm{C}\right)$, air relative humidity (\%), luminosity (lux) and cooling $\left({ }^{\circ} \mathrm{C}\right)$, humidifying (\%) and shading (lux) effect of urban forest fragments in Jataí - GO (Roda d'água forest, Ecological Park IPSG and Açude Forest)

Segundo Natel Junior (2015), existe influência da cobertura vegetal no comportamento térmico, pois em local com áreas de vegetação mais aberta, a interação entre o ar e o solo ocorre mais diretamente, tendo efeito na umidade relativa do ar e na temperatura do ar. A altura das árvores pode ser um dos fatores que também levam a isso, pois afeta a quantidade de luz que chega ao interior das florestas. Na Mata do Açude foram mesuradas árvores com mais de $30 \mathrm{~m}$, enquanto que na Mata da Roda d'água e no IPSG, a altura média encontrada foi de 19,7 e 17,8m. 
Martini et al. (2017) indicaram que os remanescentes florestais localizados em Curitiba - PR que possuem maior extensão em relação às outras tipologias estudadas apresentaram maiores valores de umidade relativa do ar. Além disso, a presença de recursos hídricos e o tamanho e formato das áreas dos remanescentes florestais do tipo mata podem justificar a maior umidade relativa do ar destes ambientes.

O grau de perturbação da Mata da roda d'água aliado ao adensamento da vegetação do Parque do IPSG e da Mata do Açude, bem como a localização em área urbanizada do Parque do IPSG, podem explicar as diferenças de temperatura do ar e luminosidade encontradas. Este fato pode indicar que devido a sua menor área de cobertura e maior suscetibilidade ao efeito de borda, que gera maior exposição de sua área à taxas de radiação incidentes nas bordas, intensificando a entrada de vento e elevando a temperatura do ar em áreas próximas a ela (SILVA, 2016). De modo geral, segundo Martini et al. (2017), a variável umidade relativa é o inverso da temperatura. Isso porque a umidade relativa é inversamente proporcional a pressão de saturação de vapor d'água que, por sua vez, é diretamente proporcional a temperatura. Assim, é possível observar em todos os cenários analisados neste experimento, o aumento da temperatura sendo inversa a umidade relativa do ar. Essa diferença entre os locais é também apontada por Rodrigues et al. (2017) em remanescentes florestais urbanos na cidade de Goiânia, estando ligada a diferenças nos elementos climáticos em relação à região da cidade, conforme a influência da cobertura e uso do solo, assim como sua localização.

O remanescente florestal que apresentou o maior efeito de resfriamento, umidificação e sombreamento foi a Mata do Açude (Figura 2). O efeito de umidificação está relacionado à diferença entre a umidade relativa do ar registrada nas áreas sem presença de árvores com o interior das áreas florestadas. Assim, quando correlacionado com as características vegetais, sombreamento, extensão da área, densidade de árvores, entrada de radiação solar e presença de cursos d'água no interior da floresta, é possível entender os fatores que levam a Mata do Açude a ser o local que apresenta maior efeito de umidificação em relação às demais. Segundo Heberle et al. (2017), a área com maior densidade de vegetação apresenta menor temperatura e maior efeito de resfriamento quando comparada a condição térmica no exterior das florestas, associando essas características a presença de cursos d'água no local e área de extensão, que também contribuem para a menor temperatura, é possível compreender a maior amplitude térmica encontrada na Mata do Açude em relação às outras áreas analisadas.

Já o menor efeito de resfriamento horizontal é encontrado na Mata da Roda d'água (Figura 2), devido à presença de clareiras no local. Isto indica que houve similaridade entre os dados de luminosidade coletados no interior do remanescente florestal e o ambiente externo. Por outro lado, Martini et al. (2017) relataram que no interior das florestas existem temperaturas máximas e mínimas menores do que em seu exterior. Assim, como esperado, a elevada 
presença de clareiras pode ter afetado a quantidade de luminosidade que alcançou o interior do remanescente florestal Mata da Roda d'água. As árvores produzem sombras e esse sombreamento protege a superfície da radiação solar. A superfície foliar que provoca 0 sombreamento utiliza a energia solar para realizar a evapotranspiração, aumentando a umidade relativa do ar e evitando que essa energia seja usada para produzir calor (MARTINI et al., 2017). Dessa forma, o sombreamento interfere tanto na umidade relativa do ar quanto na temperatura ambiente dentro das áreas florestadas.

Comparando os diferentes locais de coleta (borda, meio e interior/margem do rio) dos dados microclimáticos em cada remanescente florestal estudado, observou-se que houve diferença significativa entre os valores das variáveis temperatura e umidade, mas sem diferença significativa da variável luminosidade (Tabela 1). A radiação solar externa à área dos remanescentes florestais foi em média de $1981 \mathrm{~kJ}$.

Tabela 1. Temperatura do $\operatorname{ar}\left(\mathrm{T},{ }^{\circ} \mathrm{C}\right)$, umidade relativa do ar (UR, \%), luminosidade (L, lux) e efeito de resfriamento $\left(E R,{ }^{\circ} \mathrm{C}\right)$, umidificação (EU, \%) e sombreamento (ES, lux) em diferentes locais (borda, meio e interior) de três remanescentes florestais urbanos no município de Jataí - GO

Table 1. Air temperature $\left({ }^{\circ} \mathrm{C}\right)$, air relative humidity (\%), luminosity (lux) and cooling $\left({ }^{\circ} \mathrm{C}\right)$, humidifying (\%) and shading (lux) effect in different areas (edge, middle and interior) of urban forest fragments in the municipality of Jataí -GO (Roda d'água forest, Ecological Park IPSG and Açude Forest)

\begin{tabular}{llllllllll}
\hline \multirow{2}{*}{ Variáveis } & \multicolumn{3}{c}{ Mata da Roda d'água } & \multicolumn{3}{c}{ Parque Ecológico IPSG } & \multicolumn{3}{c}{ Mata do Açude } \\
& Borda & Meio & Interior & Borda & Meio & Interior & Borda & Meio & Interior \\
\hline $\mathrm{T}\left({ }^{\circ} \mathrm{C}\right)$ & $30,8^{a}$ & $31,2^{a}$ & $30,1^{b}$ & $30,6^{a}$ & $28,7^{b}$ & $30,2^{a}$ & $28,9^{a}$ & $28,2^{b}$ & $28,9^{a}$ \\
$\mathrm{ER}\left({ }^{\circ} \mathrm{C}\right)$ & $0,08^{a b}$ & $-0,40^{b}$ & $0,43^{a}$ & $0,21^{a b}$ & $2,14^{a}$ & $0,63^{b}$ & $1,19^{a}$ & $1,93^{a}$ & $1,20^{a}$ \\
UR $(\%)$ & $61,5^{b}$ & $61,2^{b}$ & $67,5^{a}$ & $50,2^{b}$ & $58,6^{a}$ & $52,1^{b}$ & $54,9^{b}$ & $63,5^{a}$ & $64,8^{a}$ \\
EU (\%) & $4,2^{a}$ & $3,89^{a}$ & $10,2^{b}$ & $1,26^{b}$ & $9,62^{a}$ & $3,09^{b}$ & $15,56^{a}$ & $24,20^{b}$ & $25,53^{b}$ \\
L (lux) & $772,6^{a}$ & $887,2^{a}$ & $587,7^{a}$ & $1379,6^{a}$ & $1233,4^{a}$ & $1273,7^{a}$ & $317,0^{a}$ & $280,2^{a}$ & $284,2^{a}$ \\
ES (lux) & 493,2 & 378,65 & 678,15 & 215,9 & 362,04 & 321,82 & 1278498 & 1315298 & 1339698 \\
\hline
\end{tabular}

A temperatura do ar coletada na borda, meio e interior da Mata da Roda d'água foram diferentes $(p=0,00 ; F=9,03)$, assim como do Parque do IPSG $(p=0,00 ; F=10,88)$ e da Mata do Açude $(p=0,02 ; F=4,35)$, conforme Tabela 1. A umidade relativa do ar, por sua vez, também variou entre os locais de coleta de dados (Tabela 1 ) em cada um dos remanescentes (Mata da roda d'água - $p=0,00 ; F=9,70$, Parque do IPSG - $p=0,00 ; F=12,97$; Mata do Açude $-p=$ $0,00 ; F=19,54)$.

A temperatura e umidade do ar obtidas na borda e meio da Mata da roda d'água foram superiores às encontradas no interior (margem do córrego), provavelmente devido à presença de muitas clareiras neste remanescente, exceto na margem do córrego, onde há formação de galerias acima do recurso hídrico. Na Mata do Açude, devido à sua área e não formação de galerias acima do corpo hídrico, a borda e o interior tiveram a mesma temperatura, embora a borda deste remanescente tenha menor umidade que os outros locais estudados. Por outro lado, no Parque do IPSG as condições de temperatura e umidade relativa do ar da borda se equiparou 
às encontradas na trilha (interior). As características de fisionomia, composição florística, riqueza e densidade das árvores, por consequência, podem determinar a radiação solar e o sombreamento da área, o que contribuem para a manutenção da umidade. No trabalho realizado por Lima e Mariano (2014), a análise da diferença entre os pontos dentro e fora das florestas estacionais na cidade de Caçu - GO mostrou que a falta de cobertura arbórea e a exposição das vertentes também levam os ambientes na extremidade das florestas a registrarem menores valores relacionados à umidade relativa do ar. No estudo realizado por Vilanova et al. (2009) em remanescentes florestais urbanos de Cuiabá, a umidade relativa do ar da mata de galeria variou entre 64 e 81\% no período seco. Heberle et al. (2017) aponta uma média de 54\% na área florestada por Florestas Estacionais e Ombrófila Mista, em Teutônia - RS, por ele pesquisada. Além destes, Martini et al. (2018), encontrou fora de um remanescente florestal de Curitiba - PR, no período do verão, $52,9 \%$ de umidade relativa do ar, sendo estes resultados similares aos encontrados no Parque do IPSG de Jataí - GO. Sendo assim, a maior contribuição em relação à manutenção da umidade relativa é relacionada a densidade de árvores presente que exercem influência sobre o sombreamento, precipitação, incidência de radiação solar e evapotranspiração oriundas dos indivíduos arbóreos (VILANOVA et al., 2009, ZHANG et al., 2013).

O efeito do resfriamento e da umidificação, para os três remanescentes florestais, variou em função do local estudado (Tabela 1). O efeito de sombreamento foi menor na borda que nos outros locais dos remanescentes florestais (Tabela 1), exceto na Mata do Açude, onde o efeito do sombreamento foi similar na borda, meio e interior (margem do córrego). Wang et al. (2018) também avaliou tais variáveis em diferentes tipos de florestas na China, concluindo que locais que apresentaram árvores grandes (com elevada altura e área de projeção de copa) proporcionam maior efeito de sombreamento, resfriamento e umidificação. De acordo com Heberle (2017), a cobertura vegetal influência tanto na entrada de luz e umidade relativa quanto nas variações de temperatura, uma vez que a luminosidade favorece o aumento da temperatura. Observando a variável temperatura relacionada à Mata do Açude e da Roda d'água, aquelas encontradas na borda são geralmente maiores do que as encontradas na porção mediana e no interior, enquanto que no Parque Ecológico, as maiores são encontradas na porção exterior (borda) e interior/trilha. Segundo Martini et al. (2017), isso pode ser explicado pelo efeito de borda que favorece a entrada de luz no local e a porcentagem de vegetação presente na área, já que esta é inversamente proporcional à temperatura. Nesse contexto, áreas mais abertas com menor presença de vegetação, tendem a absorver mais calor, provocando o aumento de temperatura (HEBERLE, 2017). Assim é possível compreender o aumento da temperatura na porção mediana da Mata da Roda d'água, devido às clareiras encontradas no local.

Os remanescentes florestais estudados promovem índices de conforto térmico estatisticamente diferentes (Figura 3). 


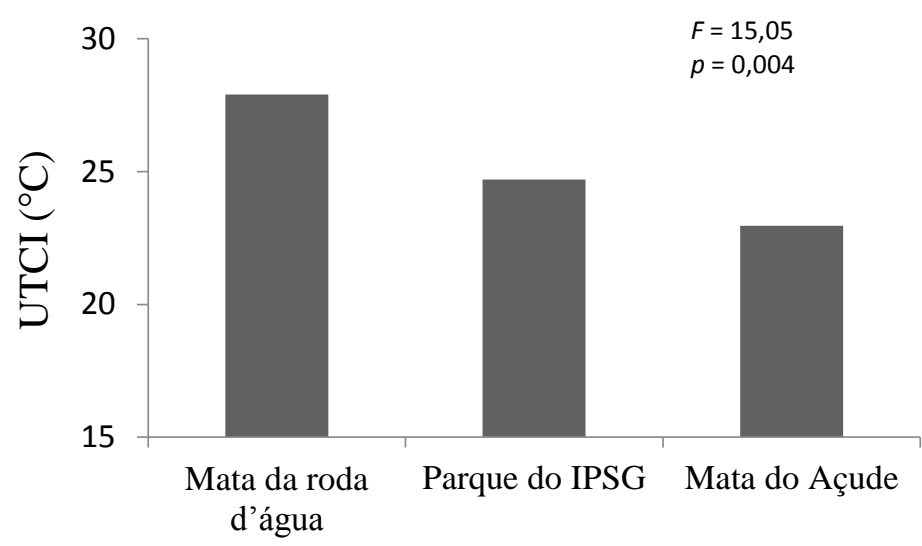

Figura 3 Média dos valores de UTCI dos remanescentes florestais de Jataí - GO Figure 3. Average values of UTCI of urban forest fragments in Jataí - GO

A Mata da roda d'água apresentou maior índice de conforto térmico quando comparada as outras florestas (Figura 3), pois quanto maior índice de conforto térmico (UTCI), maior o estresse gerado principalmente pela temperatura. Dessa forma, a Mata da roda d'água apresentou moderado estresse para calor, enquanto que o Parque do IPSG e a Mata do Açude não apresentaram estresse térmico (UTCI inferiores a $26^{\circ} \mathrm{C}$ ), segundo Blażejczyk et al. (2010). Martini e Biondi (2015), ao compararem os valores médios de UTCI de diferentes ambientes (fragmento de floresta com gramado, bosque de pinus e estacionamento), em diferentes estações do ano em Curitiba - PR, mostraram que os valores de UTCI do fragmento foram muito similares aos encontrados neste estudo. Além disso, estas autoras demonstraram que, na maior parte das análises, o ambiente com maior capacidade de interceptar os raios solares diretamente, entre outras possibilidades, foram aqueles que proporcionaram maior conforto térmico (fragmento florestal).

O índice de conforto térmico proporcionado pela borda do Parque Ecológico do IPSG foi superior aos outros locais estudados neste remanescente florestal (Tabela 2). Por outro lado, tanto na Mata da roda d'água quanto na Mata do Açude apresentaram índice de conforto térmico da borda semelhante ao interior da floresta. A localização do remanescente, ou seja, a proximidade ou distanciamento das áreas mais urbanizadas do município pode explicar essa diferença entre os locais de coleta de dados dos remanescentes. Martini et al. (2018) demonstraram a diferença existente entre o interior e o entorno imediato das diferentes tipologias das florestas urbanas, sendo o remanescente florestal uma das tipologias que foram observados maior diferença entre o ambiente interno e externo.

Tabela 2. Conforto térmico proporcionado por diferentes locais (borda, meio e interior) de remanescentes florestais urbanos no município de Jataí - GO (Mata da Roda d'água, Parque Ecológico do IPSG e Mata do Açude) 
Table 2. Thermal comfort provided by different areas (edge, middle and interior) in urban forest fragments in the municipality of Jataí - GO (Roda d'água Forest, Ecological Park IPSG and Açude Forest)

\begin{tabular}{ccccc}
\hline \multirow{2}{*}{ Ambientes } & \multicolumn{4}{c}{ Conforto Térmico } \\
\cline { 2 - 5 } & Borda & Meio & Interior & ANOVA \\
\hline Mata da roda d'água & $27.80^{a b}$ & $28.70^{a}$ & $27.20^{b}$ & $F: 5,814 ; p: 0,007$ \\
Parque Ecológico do IPSG & $26.10^{a}$ & $22.90^{b}$ & $25.10^{a b}$ & $F: 6,263 ; p: 0,006$ \\
Mata do Açude & $22.9^{a b}$ & $22.30^{b}$ & $23.70^{a}$ & $F: 3,523 ; p: 0,043$ \\
\hline
\end{tabular}

Nota: Valores marcados com a cor verde representam locais possuem conforto térmico (sem estresse térmico), enquanto que os marcados com a cor rosa referem-se a locais com moderado estresse térmico para calor (desconforto), segundo Blażejczyket al. (2010).

De acordo com Blażejczyket al. (2010), os três ambientes da Mata da Roda d'água e a borda do Parque Ecológico do IPSG apresentaram moderado estresse térmico para calor (Tabela 3). Por outro lado, todos os locais da Mata do Açude, bem como o meio e o interior do Parque do IPSG foram classificados como sem estresse térmico. Tanto a morfologia quanto a tipologia dos remanescentes florestais influenciam no conforto térmico (JUSTI et al., 2019; MARTINI; BIONDI, 2015; MARTINI et al., 2018), Além disso, o grau de perturbação (elevado número de clareiras) e a proximidade com áreas urbanizadas podem justificar o desconforto dos locais estudados. Dessa forma, áreas mais conservadas, independentemente de sua forma e área, podem promover conforto térmico nas cidades. Isto reforça a necessidade de criação, conservação e manutenção das florestas urbanas, o que impacta diretamente na qualidade de vida da população residente.

A partir desses resultados é possível observar que a vegetação exerce diversas funções para o controle do clima, entre elas a de proporcionar sombra, resfriar o ar, aumentar a umidade e proporcionar conforto térmico. A radiação visível absorvida pelos vegetais é utilizada na evapotranspiração, o que contribui para as trocas de calor latente (trocas térmicas úmidas), trazendo a umidificação do ar. Portanto, a vegetação, além de absorver a radiação solar excessiva (sombreamento), atua no resfriamento e na umidificação do ar, contribuindo, em ambas as vias, para o estabelecimento de microclimas mais agradáveis. Uma vez que, mesmo em "moderado estresse térmico para calor", a sensação térmica no interior da floresta foi mais agradável do que em seu exterior. A presença de cursos d'água, o tamanho da área e as clareiras encontradas em seu interior foram determinantes para a verificação do efeito das florestas urbanas sobre o microclima e o conforto térmico.

\section{CONCLUSÕES}

A Mata do Açude proporciona microclima mais confortável do que as demais florestas analisadas, sobretudo devido a sua forma, presença de cursos d'água, arquitetura das copas e poucas clareiras. As bordas das florestas, como esperado, apresentam microclima diferente do 
interior das florestas. A Mata da Roda d'água apresenta menor conforto térmico entre as florestas analisadas, devido à elevada quantidade de clareiras, pela elevada radiação solar e umidade relativa do ar. A Mata do Açude e o meio e trilha do Parque IPSG apresentam ausência de estresse térmico enquanto que a Mata da Roda d'água e a borda do Parque IPSG apresentam moderado estresse para calor.

\section{AGRADECIMENTOS}

À Fundação de Apoio à Pesquisa do Estado de Goiás - FAPEG, à Prefeitura Municipal de Jataí/Secretaria de Meio Ambiente e Urbanismo, ao Instituto Presbiteriano Samuel Graham, à Nayara Alves Ferreira e aos estudantes graduandos em Engenharia Florestal que auxiliaram na coleta de dados.

\section{REFERÊNCIAS}

BIONDI, D. Floresta urbana: conceitos e terminologias. In: BIONDI, D. (Org.). Floresta Urbana. Curitiba: A autora, 2015. p. 11-27.

BLAZERJCZYKL, K.; BROEDE, P.; FIALA, D.; HAVENITH, G.; HOLMER, I.; JENDRITZKY, KAMPMANN, B.; KUNERT, A. Principles of the new thermal climate índex (UTCI) and its aplication to bioclimatic research in Euripean Scale. Miscellanea Geographica, Varsovia, v. 14, n. 1, p. 91-102, 2010.

DACANAL, C.; LABAKI, L. C.; SILVA, T. M. L. Vamos passear a floresta! O conforto térmico em fragmentos florestais urbanos. Ambiente Construído, Porto Alegre, v. 10, n. 2, p. 115-132, 2010.

FERREIRA, E. S.; OLIVEIRA, A. M. S. Análise da interface da floresta urbana do Parque Estadual da Cantareira, núcleo Cabuçi em Guarulhos - SP. Revista Educação, São Paulo, v. 11, n. 3, p. 1, 2016.

HEBERLE, M.; SILVA, B. M. D. C; LIMA, C. S.; QUINTAL, R. S.; REMPEL, C. DALZOCHIO, M. S. Variações no microclima e características do solo em paisagens com diferentes coberturas vegetais: ação de campo junto ao Morro da Harmonia - Teutônia/RS. Destaques acadêmicos, Lajeado, v. 9, n. 3, p. 283-295, 2017.

Instituto Nacional de Meteorologia (INMET). Estação Meteorológica de Observação de Superfície Automática em Jataí-GO. Disponível em:<http://www.inmet.gov.br/sonabra/ pg_dspDadosCodigo_sim.php?QTAxNg==> Acesso em: 30 mai. 2018.

INSTYTUT GEOGRAFII I PRZESTRZENNEGO ZAGOSPODAROWANIA (IGPZ). Bioklima. Disponível em: <http://www.igipz.pan.pl/Bioklima-zgik.html> Acesso em: 18/06/2019. 
JÚNIOR, A. F.; ESTEVÃO, C. I. M.; SOUZA, L. R.; LOPES, P. A.; FERREIRA, W. C. Caracterização de um fragmento urbano de mata atlântica em Goiás. Enciclopédia Biosfera, Goiânia, v. 13, n. 24; p. 197-211, 2016.

JUSTI, A. C. A.; NOGUEIRA, M. C. J. A.; SANTOS, F. M. M.; MUSIS, C. R. M.; NOGUEIRA, J. S. Impacto da morfologia de parque urbano no microclima e no conforto térmico de Cuiabá Brasil. Revista Brasileira de Climatologia, Curitiba, v. 24, p. 20-38, 2019.

LABAKI, L. C.; SANTOS, R. F.; BUENO-BARTHOLOMEI, C. L.; ABREU, L. V. A. Vegetação e conforto térmico em espaços urbanos abertos. Fórum Patrimônio, Belo Horizonte, v. 4, n. 1, p. 23-42, 2011.

LIMA, A. M.; MARIANO, Z. F. Análise microclimática no interior e fora das florestas estacionais semideciduais na área da bacia da usina hidrelétrica de Caçu - GO. Revista do Departamento de Geografia, Caçu, v. 27, p. 67-87, 2014.

MARTINI, A.; BIONDI, D. Microclima e conforto térmico de um fragmento de floresta urbana em Curitiba, PR. Floresta e Ambiente, Seropédica, v. 22, n. 2, p. 182-193, 2015.

MARTINI, A.; BIONDI, D.; BATISTA, A. C. As diferenças microclimáticas entre as tipologias de floresta urbana e dados registrados pela estação meteorológica oficial. Scientia Plena, Curitiba, v. 13, n. 3; p. 1-7, 2017.

MARTINI, A; BIONDI, D; BATISTA, A. C.; SILVA FILHO, D. F. da Análise microclimática das diferentes tipologias de floresta urbana de Curitiba. Floresta, Curitiba, v. 47, n. 2, p 137-144, 2017.

MARTINI, A.; BIONDI, D.; BATISTA, A. C. A influência das diferentes tipologias de floresta urbana no microclima do entorno imediato. Ciência Florestal, Santa Maria, v. 28, n. 3, p. 9971007, 2018.

NASCIMENTO, D. T. F.; OLIVEIRA, I. J. de Análise da evolução dos fenômenos de ilhas de calor no município de Goiânia/GO (1986-2010). Boletim Goiano de Geografia, Goiânia, v. 31, n. 2, p. 113-127, 2011.

NATEL JUNIOR, Vilson Luiz Ferreira. A influência da vegetação sobre o clima urbano de Curitiba-PR: estudo de caso. Curitiba, 2015. 23f. Especialização (Especialização em Análise Ambiental) Universidade Federal do Paraná - UFPR. Curitiba, 2015.

OLIVEIRA, L. C. S.; GUIMARÃES, J. C. O.; SOUZA, I. C. S.; LIMA, C. M.; FERREIRA, W. C. Levantamento florístico e fitossociológico da regeneração natural de uma mata de galeria localizada no município de Jataí - GO, Global Science and Technology, Rio Verde, v. 8, n. 3, 2015.

RODRIGUES, A. P. M.; PASQUALETTO, A.; GARÇÃO, A. L. O. A influência dos parques urbanos no microclima de Goiânia. Revista Brasileira de Assuntos Regionais e Urbanos, Goiânia, v. 3, n. 1, 2017.

SCOPEL, I.; KATZER, R. T.; SILVA, M. R.; MELO, A. N.; PEIXINHO, M. D. Evolução do uso da Terra na microbacia do córrego do açude, em Jataí - GO. Boletim Goiano de Geografia, Goiânia, v. 22, n. 2, p.31-46, 2002. 
SILVA, B. A.; XAVIER, T. C.; ALVAREZ, C. E. A influência da vegetação no conforto térmico para a condição microclimática de Vitória (ES). Periódico Técnico e Científico Cidades Verdes, Tupã, v. 3, n. 8, p. 01-15, 2015.

SILVA, M. F. A.; SANTOS, M. N.; SANTOS, C. E. L.; WHITE, B. L. A. Avaliação da temperatura do solo, temperatura do ar e umidade relativa do ar em uma clareira de mata atlântica no município de São Cristóvão, Sergipe, Brasil. Agroforestalis News, Aracaju, v. 1 n. 1, p. 58-62, 2016.

VILANOVA, S. R. F.; MAITELLI, T. G. A. importância da conservação de áreas verdes remanescentes no centro político administrativo de Cuiabá - MT. Uniciência, Brasília, v. 13, n. 1, p. 53-71, 2009.

WANG, W.; WANG, H.; XIAO, L.; HE, X.; WANG, Q.; WEI, C. Microclimate regulating function of urban forests in Changchun City (northeast China) and their associations with different factors. iForest, Viterbo, v. 11, p. 140-147, 2018.

ZHANG, Z.; Lv, Y.; Pan, H. Cooling and humidifying effect of plant communities in subtropical urban parks. Urban Forestry and Urban Greening, v. 12, p. 323-329, 2013. 